\title{
Modeling the infiltration capacity of permeable stormwater channels with a check dam system
}

\begin{abstract}
The use of permeable stormwater channels has introduced concerns over the effects of infiltration on the hydraulic behavior of their flow and the effects of flow hydraulic conditions (e.g., the water level, channel section, flow velocity, and vegetation) on the channel infiltration capacity. A check dam system provides backwater ponding, which increases the flow water depth along a channel. In this study, a channel model was used to investigate the variation in the infiltration capacity of permeable stormwater channels under different flow hydraulic conditions. Increasing the downstream check dam height and using a grass cover increased the infiltration rate and cumulative infiltration because of the decreased velocity and increased flow depth. The presence of subsurface water did not affect the hydraulic characteristics of the channel flow but decreased the cumulative infiltration because of the fast saturation of the soil. An empirical equation was developed for predicting the infiltration capacity of grassed channels in which four hydraulic parameters (i.e., the water depth, base width, side slope, and velocity) are introduced to the modified Kostiakov model. The developed model was used to calculate the runoff reduction due to infiltration along a grassed channel with and without a check dam system. The percentage of infiltrated water increased from 8 to $14 \%$ with the check dam system. The developed model can be used to predict the infiltration capacity of permeable channels for improved stormwater management and provides a valuable decision support tool for permeable channel design.
\end{abstract}

Keyword: Stormwater; Permeable channel; Infiltration capacity; Modified Kostiakov model; Check dam system 